\title{
Effects of the use of a wavy cap on the tip of the colonoscope on the training performance of novice endoscopists for colonoscopy
}

\author{
NAOYA TOYOSHIMA, SHIN-EI KUDO, YUICHI MORI, MAKOTO KUTSUKAWA, \\ TATSUYA SAKURAI, YUTA KOUYAMA, MASASHI MISAWA, TOYOKI KUDO, TAKEMASA HAYASHI, \\ KUNIHIKO WAKAMURA, HIDEYUKI MIYACHI, TOSHIYUKI BABA and FUMIO ISHIDA
}

Digestive Disease Center, Showa University Northern Yokohama Hospital, Yokohama-shi, Kanagawa 224-8503, Japan

Received August 3,2020; Accepted December 11, 2020

DOI: $10.3892 /$ wasj.2020.79

\begin{abstract}
Trainee doctors have to perform numerous procedures to master the colonoscopy technique. The present study aimed to compare the efficacy of colonoscopy with and without the use of a wavy cap based on the total colonoscopy (TCS) rate and the insertion time achieved by the trainee. A 6-month prospective study was conducted at Showa University Northern Yokohama Hospital between May and October, 2011. A total of 5 trainee doctors were randomly allocated to the cap group that performed colonoscopies using a wavy cap on the endoscope ( $n=2$ trainees) or the non-cap group that used no cap ( $\mathrm{n}=3$ trainees). All evaluated patients underwent initial TCS using a magnifying video colonoscope. The insertion time and TCS rate were recorded. The primary endpoint was the comparison of the caecum arrival rate between the cap and non-cap groups following 6 months of training. In total, 276 colonoscopies using a cap and 387 colonoscopies without a cap were performed. The cecal intubation time of the cap group was significantly shorter than that of the non-cap group ( 9.2 vs. $11.6 \mathrm{~min}, \mathrm{P}<0.001)$. The TCS rate by the novice endoscopists in the cap group was significantly greater than that of the non-cap group (41.7 vs. $33.8 \%, \mathrm{P}=0.036$ ). After 60 procedures, the learning curve of the cap group was significantly steeper than that of non-cap group. On the whole, the findings of the present study suggest that the use of a wavy cap on the tip of the colonoscope is helpful for achieving a higher cecal intubation rate, a more rapid insertion time and a steep learning curve for novice endoscopists.
\end{abstract}

\section{Introduction}

The incidence of colorectal cancer (CRC) throughout Japan has been increasing, rendering colonoscopy a useful tool for

Correspondence to: Professor Shin-Ei Kudo,Digestive Disease Center, Showa University Northern Yokohama Hospital, 35-1 Chigasaki-Chuo, Tsuzuki-ku, Yokohama-shi, Kanagawa 224-8503, Japan

E-mail:kudos@med.showa-u.ac.jp

Key words: cap-assisted colonoscopy, insertion, learning curve, wavy cap the diagnosis, treatment and screening of CRC. Although the annual 2-day fecal immunochemical test (FIT) is commonly used in population-based CRC screening programs in Japan, total colonoscopy (TCS) has recently been applied in situations, such as CRC screening during medical check-up examinations. Furthermore, colonoscopy and polypectomy have effectively reduced the incidence of CRC (1-3).

The rate of TCS and insertion time are important markers for progress being made in colonoscope training. However, the TCS technique is difficult, and mastering this technique requires considerable time, effort and practice (that is, a large number of cases are required) (4-7). Delayed or failed cecal intubation can have unfavorable results, such as patient discomfort, complications and consecutive cecal re-insertion failure. Various factors have been implicated in the performance of trainees and success in performing colonoscopy. One of the issues is that trainees tend to experience difficulty in detecting the next lumen. Experts in colonoscopy can be judged by the manner in which they insert the colonoscope into the oral side without any complications by experience.

Cap-assisted colonoscopy (CAC) is a useful modality for detecting lesions. In fact, CAC was developed to improve polyp and adenoma detection (8-16). CAC is particularly useful as the cap can depress the semilunar folds, allowing the endoscopist to inspect the blind mucosal area. The wavy cap is shorter than the conventional cap, and this characteristic provides the wavy cap with the advantage of not causing an eclipse on the endoscopy screen during magnified observation. In addition, the wavy cap is designed to be advantageous for flipping folds at the tip of the endoscope during insertion. It is considered that a wavy cap (MAJ-Y0024-2; Olympus Corporation) may help trainees to rapidly and promptly acquire the TCS technique. The aim of the present study was to compare the efficacy of colonoscopy using a wavy cap compared with colonoscopy without a cap based on the TCS rate and insertion time achieved by the trainee.

\section{Materials and methods}

Study population. This comparative prospective trial was conducted between May and October, 2011. When the 5 novice endoscopists (who had each performed $<10$ colonoscopies) began working in routine clinical practice at Showa University Northern Yokohama Hospital in May, 
2011, they were randomly allocated to either the cap group (Dr Yui Jennyfer Oka, Dr Tatsuya Sakurai and Dr Tetsuya Yoshizaki) or the non-cap groups (Dr Yu-ta Koyama and Dr Shinichi Kataoka). The study flowchart is presented in Fig. 1. A total of 3,650 patients underwent colonoscopy at Showa University Northern Yokohama Hospital between May and October, 2011. The 5 novice endoscopists performed 680 of these colonoscopies (without any arbitrary patient selection). Among these 680 patients, those with the following criteria were excluded: i) emergency colonoscopy; ii) colon obstruction; iii) inflammatory bowel disease; and iv) poor bowel preparation (particularly when hard impacted stool was found in the rectosigmoid area). Hence, 667 colonoscopies were eligible for inclusion as follows: A total of 276 colonoscopies performed by the cap group, and 387 performed by the non-cap group. The study protocol was approved by the Ethics Committee at Showa University Northern Yokohama Hospital (no. 1105-03). The study was registered at ClinicalTrials.gov under the identifier NCT01400087, and it was conducted in accordance with the Declaration of Helsinki. All patients provided written informed consent prior to participation in the study. Part of the present study was presented at the Digestive Disease Week 2016, San Diego, CA, USA, May 1, 2016 (poster presentation).

Training program and study design. This colonoscopy training program was conducted only with the condition that patients did not suffer any discomfort. Initially, the trainees practiced the endoscopic techniques for upper endoscopy and colonoscopy using the 'Colonoscopy training model' (KY11361-000, Olympus Corporation), with the goal of performing cecal intubation within $15 \mathrm{~min}$. Once the trainees had achieved this goal, they spent 2 weeks observing experienced endoscopists perform colonoscopies. The experienced endoscopists instructed the trainees on the use of a colonoscope insertion method named the ' $3 \mathrm{~S}$ technique': Straight insertion, slide laterally, shortening. First, the colonoscope is straightened. Second, the endoscopist then slides the colonoscope to pass the fold. Third, the colon is shortened by pulling back the colonoscope. The senior endoscopists allowed the trainees to perform the colonoscopy procedure after ensuring that the procedures could be performed under safe and comfortable conditions for the patients. However, the senior endoscopists intervened during the procedure in the following cases: i) if the trainee could not reach the cecum within $15 \mathrm{~min}$; ii) if the patients asked for the procedure to be performed by senior endoscopists; or iii) the trainee felt uncomfortable about performing the procedure. Cecal intubation was documented by photographing the identified cecal landmarks, such as the appendiceal orifice and the ileocecal valve. Patient age, sex, body mass index (BMI) and surgical history were recorded prior to the procedure. The trainee began the insertion after bowel preparation was completed, and the cecal intubation time was recorded. Following cecal intubation, the trainee and the senior endoscopists carefully examined the colon during the withdrawal of the colonoscope; biopsies and/or treatment were performed as needed.

All patients underwent initial TCS using a magnifying video colonoscope (CF-H260AZI; Olympus Corporation). The cap group used a wavy cap (MAJ-Y0024-2; Olympus
Corporation; Fig. 2) on the tip of the colonoscopes during every colonoscopy. Moderate sedation was induced with a combination of intravenous diazepam or midazolam and meperidine in almost all the patients, apart from those who refused sedation. The quality of the colonoscopies was monitored during the 6 -month training period. The TCS rate by novice endoscopists, insertion time and learning curve were evaluated for each group. The trainee learning curves were calculated in consecutive blocks of 20 procedures. The primary endpoint was the comparison of the cecum arrival rate between the cap and non-cap groups after 6 months of colonoscopic training.

Sample size calculation. The sample size was calculated using the Chi-squared test based on previous results indicating that after 3 months, the cecal arrival rate was significantly higher in the cap group than that in the non-cap group. At Showa University Northern Yokohama Hospital the cecal arrival rate in the non-cap group (trainees without TCS experience who received TCS training for 3 years) in a 3-month period was approximately $13.5 \%$. In a previous study, the insertion rate increased by $1.6 \%$ when comparing the non-cap group with the cap group (9). In the present study, it was estimated that the insertion rate would be $10 \%$, considering that the trainees had performed under 100 cases of TCS. Assuming an insertion rate of $23.5 \%$ for the cap group and $13.5 \%$ for the non-cap group, the sample size was calculated. All tests were two-sided with an alpha level of 0.05 and a power of 0.80. Subsequently, 235 patients were enrolled in each group, considering a potential dropout of cases of approximately $10 \%$, yielding a target sample size of 500 patients in total.

Statistical analyses. All statistical analyses were performed using SPSS version 19.0 software (SPSS, Inc.) and BellCurve for Excel (Social Survey Research Information Co., Ltd.). All continuous variables are expressed as the means \pm standard deviation (SD). Continuous variables of clinical features of enrolled patients and cecal intubation time were analyzed using the Student's t-test. Categorical data of clinical features of enrolled patients and rate in total cases were assessed with the Chi-squared test. In analyzing the intubation time and the success rate in the consecutive blocks of 20 procedures, a two-way repeated measures analysis of variance (ANOVA) was used followed by the Bonferroni multiple comparison test. A P-value $<0.05$ was considered to indicate a statistically significant difference.

\section{Results}

Baseline demographic and clinical data of patients. Between May and October, 2011, 680 consecutive patients were prospectively enrolled who were scheduled to undergo colonoscopy at Showa University Northern Yokohama Hospital. A total of 5 trainee doctors were randomly allocated to 2 groups as follows: the cap group (2 doctors) and the non-cap group (3 doctors). In total, 276 colonoscopy cases were performed with cap and 387 cases without cap. A total of 17 cases were excluded due to the following reasons: Bowel stenosis with colon cancer $(n=2)$, ischemic colitis $(n=3)$ and change to another scope (thin scope or long scope) $(n=12)$. The mean (SD) age of the patients was 62.5 (13.7) years, and 


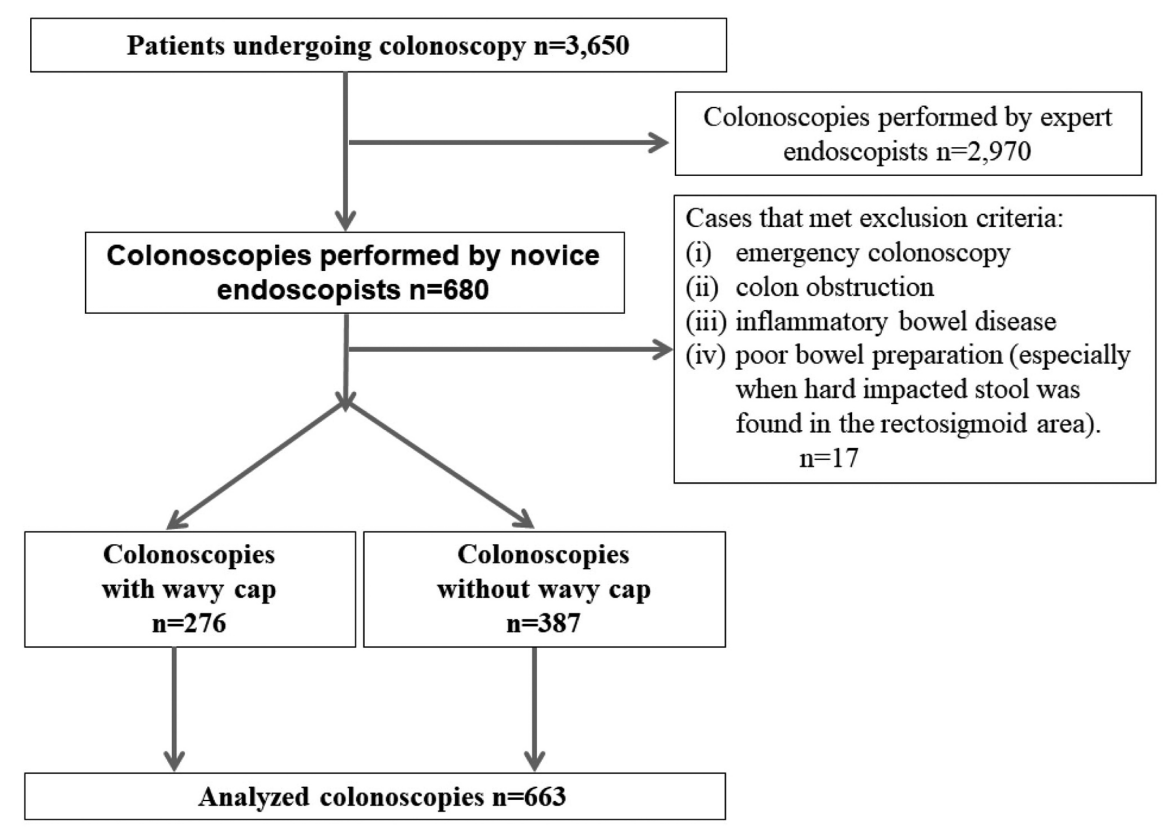

Figure 1. Flowchart of the present study. Of the 3,650 colonoscopies performed at Showa University Northern Yokohama Hospital. between May and October, 2011, 680 were performed by 6 novice endoscopists. After excluding 17 cases based on the exclusion criteria and 4 cases in which the trainees required expert assistance, 663 colonoscopies were included. The cap group performed 276 colonoscopies, whereas the non-cap group performed 387 colonoscopies.

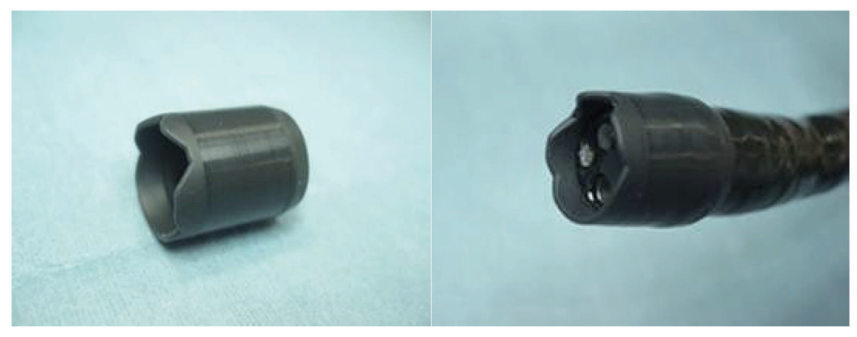

Figure 2. The wavy cap (MAJ-Y0024-2, Olympus Corporation) used on the tip of the colonoscope during every colonoscopy performed by the cap group. The image on the left panels illustrates a wavy cap, and the image on the right panel illustrates a wavy cap attached to the endoscope.

the mean BMI was $22.7(3.3) \mathrm{kg} / \mathrm{m} 2$. Of the included subjects, 420 were males $(63.3 \%)$ and 243 were women $(36.7 \%)$. There were 318 patients $(48.0 \%)$ without a history of surgery, and $18.1 \%$ had a history of colorectal surgery. Additionally, $18.6 \%$ of the patients suffered from constipation. There were no significant differences in background demographic and clinical characteristics of the patients between the cap and non-cap groups. The demographic data are summarized in Table I.

Cecal intubation time. The mean (SD) cecal intubation time (time to reach the cecum with the colonoscope) was 15.7 (6.8) $\mathrm{min}$ in the cap group and 19.11 (7.6) $\mathrm{min}$ in the non-cap group $(\mathrm{P}<0.001)$ (Table II). The expert endoscopist assisted in all cases in which the novice endoscopists could not perform TCS within $15 \mathrm{~min}$. The skill of the trainee in performing cecal intubation in $<15$ min improved rapidly and significantly within all blocks. Based on the learning curve of the cecal intubation time, the cap group exhibited a significantly faster than the non-cap group in all blocks (Table III and Fig. 3).
Cecal insertion rate. Cecal intubation was achieved in all cases by the trainee and senior endoscopists. The success rate of cecal intubation by the trainees was 115/276 (41.7\%) in the cap group and 131/387 (33.8\%) in the non-cap group $(\mathrm{P}=0.036)$ (Table II). After 60 procedures, the cap group exhibited a significantly steeper learning curve than the non-cap group (Table IV and Fig. 4). During this program, no complications were encountered in either treatment group.

\section{Discussion}

The incidence of CRC worldwide has been increasing, rendering colonoscopy a useful tool for the diagnosis, treatment, and screening of CRC. Additionally, colonoscopy with polypectomy is one of the most effective procedures for preventing CRC. Reportedly, colonoscopy with polypectomy has effectively reduced the incidence of CRC $(2,3)$. However, the technique of TCS is difficult and doctors need to perform numerous procedures to acquire expertise and proficiency in this technique. Even for experts, it is not always possible to reach the cecum (17). The TCS technique is evaluated by 2 important parameters: insertion time and TCS rate.

A short cecal intubation time is important for several reasons: Less anesthetic medication is required, colonic inflation tends to result in less discomfort, and it allows sufficient withdrawal time for accurate colon examination. TCS requires extremely low air insufflations. Experts can advance a colonoscope by pushing and pulling using meticulous lever manipulation without air insufflation, especially in the rectum and sigmoid colon. This ability can prevent the mucosa from touching the lens directly and enables continuous lumen observation with low air. One potentially promising technique is CAC. A transparent cap (or hood), a simple plastic device, can be attached to the tip of a colonoscope before performing the colonoscopy. Several randomized trials (8-12) conducted 
Table I. Demographics and clinical features of the enrolled patients.

\begin{tabular}{|c|c|c|c|c|}
\hline Characteristics & Total no. of patients, $n=663$ & Cap group, $n=276$ & Non-cap group, $n=387$ & P-value \\
\hline Sex (male), n (\%) & $420(63.3)$ & $166(60.1)$ & $254(65.6)$ & $>0.05^{\mathrm{a}}$ \\
\hline Age, years, mean (SD) & $62.5(13.7)$ & $63.1(13.5)$ & $62.1(13.9)$ & $>0.05^{\mathrm{b}}$ \\
\hline BMI, kg/m², mean (SD) & $22.7(3.3)$ & $22.7(3.3)$ & $22.6(3.4)$ & $>0.05^{\mathrm{a}}$ \\
\hline Previous surgery, n (\%) & $345(52.0)$ & $146(52.9)$ & $199(51.4)$ & $>0.05^{\mathrm{a}}$ \\
\hline Colorectal surgery, n (\%) & $120(18.1)$ & $47(17.0)$ & 73 (18.9) & $>0.05^{\mathrm{a}}$ \\
\hline Others, $\mathrm{n}(\%)$ & 225 (33.9) & 99 (35.9) & $126(32.6)$ & $>0.05^{\mathrm{a}}$ \\
\hline Constipation, n (\%) & $123(18.6)$ & $53(19.2)$ & $70(18.1)$ & $>0.05^{\mathrm{a}}$ \\
\hline
\end{tabular}

${ }^{a}$ These data were analyzed using the Chi-squared test; ${ }^{b}$ these data were analyzed using the $\mathrm{t}$-test; data for insertion time are presented as the means (SD). BMI, body mass index.

Table II. Cecal intubation time and rate in total cases.

\begin{tabular}{lccc}
\hline Time or rate & Cap & Non-cap & P-value \\
\hline Insertion time, min & $15.7(6.8)$ & $19.11(7.6)$ & $<3.8$ \\
Cecal insertion rate $(\%)$ & 41.7 & 33.8 & $0.031^{\text {a }}$ \\
\hline
\end{tabular}

${ }^{a}$ Data were analyzed using the t-test; data for insertion time are presented as the means (SD). ${ }^{b}$ Data were analyzed using the Chi-squared test.

Table III. Cecal intubation time in each 20 cases.

\begin{tabular}{lccr}
\hline Case number (groups of 20 procedures) & Cap (min) & Non-cap (min) $^{\mathrm{a}}$ & P-value $^{\mathrm{b}}$ \\
\hline $1-20$ & $19.0 \pm 1.0$ & $21.0 \pm 0.8$ & 0.02 \\
$21-40$ & $17.7 \pm 0.1$ & $20.2 \pm 0.4$ & $<0.01$ \\
$41-60$ & $17.5 \pm 1.4$ & $20.6 \pm 2.5$ & $<0.01$ \\
$61-80$ & $14.0 \pm 1.6$ & $19.2 \pm 3.7$ & $<0.01$ \\
$81-100$ & $14.7 \pm 0.7$ & $18.2 \pm 1.0$ & $<0.01$ \\
\hline
\end{tabular}

${ }^{a}$ Data are expressed as the means \pm standard deviation. ${ }^{b}$ Bonferroni's multiple comparison test following ANOVA was used to compare the time required for successful cecal intubation among the consecutive blocks of 20 procedures.

in Japan have reported mixed results regarding improved cecal intubation times and polyp detection rates when using the cap. Transparent caps attached to the distal tip of the colonoscope were first designed to assist during endoscopic mucosal resection. However, it has also been suggested that such caps are helpful for depressing colonic folds, and thus, improve the visualization of their proximal aspects. CAC can be easily implemented by simply attaching a transparent rubber cap to the tip of the colonoscope, and its use has been associated with a decrease in the cecal intubation time, without increasing the cost of the procedure $(9,12-17)$.

Additionally, the cap allows for an appropriate distance between the colonic mucosa and the lens of the colonoscope. Additionally, the cap can be used to stretch or splay the colonic mucosa, further contributing to improved detection rates $(9,18,19)$. Previous studies have demonstrated that CAC is more effective than non-CAC for the detection of colorectal polyps and adenomas, particularly in difficult cases, those in which the procedure is performed by trainees, and cases in which the lesions are located in the right-side colon $(17,18)$. The endoscopic cap also reportedly improves the adenoma detection rate, visualization of the ampulla of Vater and sclerotherapy for hemorrhoids $(22,23)$. A previous study demonstrated that CAC may be of benefit in terms of cecal intubation time and insertion rate. In the present study, the learning curve revealed that the insertion rate increased significantly at approximately 60 procedures. It is considered that these number of cases were necessary, as the endoscopists in the present study had minimal previous experience in performing endoscopies. The rate of cecal intubation did not differ significantly between the 2 groups during the first 60 cases, whereas the usefulness of the wavy cap for cecal intubation appeared when the number 
Table IV. Cecal intubation rate in each 20 cases.

\begin{tabular}{lccr}
\hline Case number (groups of 20 procedures) & Cap (\%) & Non-cap (\%) & P-value $^{\mathrm{a}}$ \\
\hline $1-20$ & 17.5 & 20.0 & 0.69 \\
$21-40$ & 27.5 & 28.3 & 0.89 \\
$41-60$ & 27.5 & 28.3 & 0.89 \\
$61-80$ & 52.5 & 36.7 & 0.03 \\
$81-100$ & 57.5 & 30.0 & $<0.01$
\end{tabular}

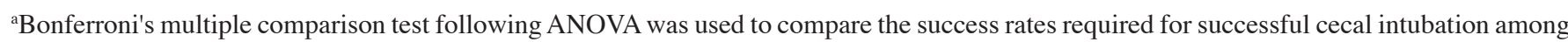
the consecutive blocks of 20 procedures.

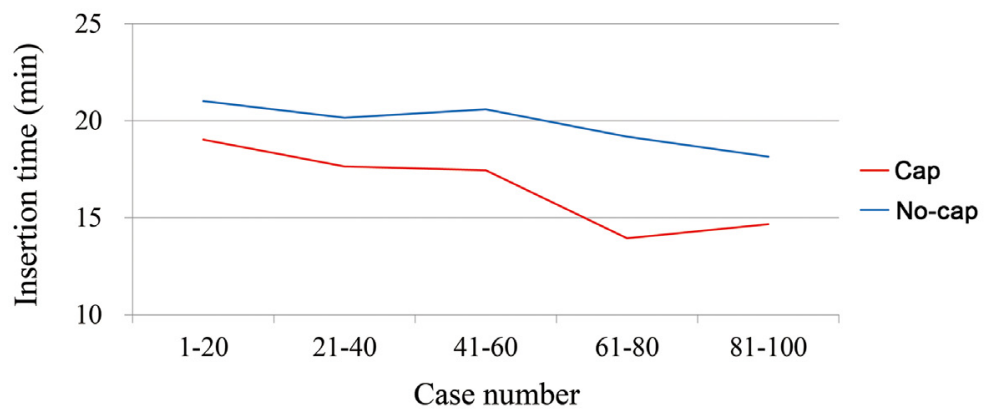

\begin{tabular}{|c|r|c|}
\hline Case number & P-value & $* \mathrm{P}<0.05, * * \mathrm{P}<0.01$ \\
\hline $1-20$ & 0.0217 & $*$ \\
\hline $21-40$ & 0.0067 & $* *$ \\
$41-60$ & 0.0016 & $* *$ \\
$61-80$ & $\mathrm{P}<0.0001$ & $* *$ \\
\hline $81-100$ & 0.0008 & $* *$ \\
\hline
\end{tabular}

Figure 3. Learning curve for insertion time. Association between each 20-case block and the insertion time for cap group and non-cap group. ANOVA and Bonferroni's multiple comparison test was used to compare the time required for successful cecal intubation among the consecutive blocks of 20 procedures. The red line represents the cap group and the blue line represents the non-cap group.

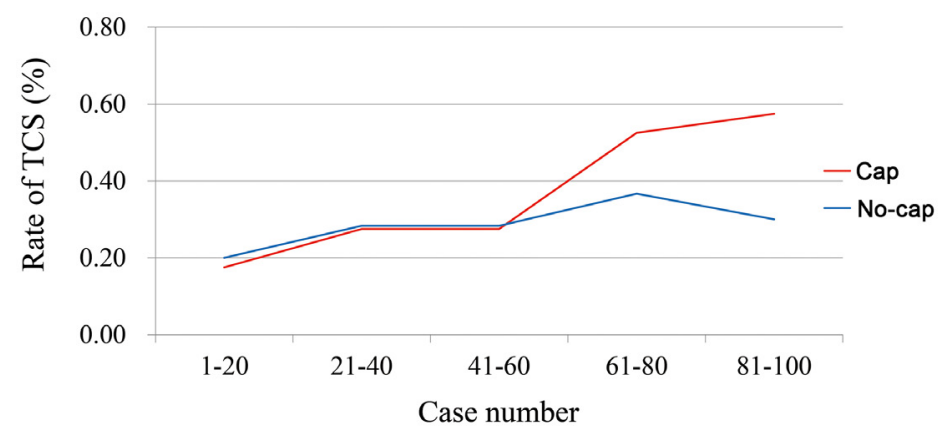

\begin{tabular}{|c|c|c|}
\hline Case number & P-value & $* \mathrm{P}<0.05 * *, \mathrm{P}<0.01$ \\
\hline $1-20$ & 0.6859 & \\
\hline $21-40$ & 0.8922 & \\
\hline $41-60$ & 0.8922 & \\
\hline $61-80$ & 0.0320 & $*$ \\
\hline $81-100$ & 0.0024 & $* *$ \\
\hline
\end{tabular}

Figure 4. Learning curve for cecal insertion rate. Association between each 20 -case block and the success rate (successful cecal intubation within 15 min) for cap group and non-cap group. ANOVA and Bonferroni's multiple comparison test was used to compare the success rates required for successful cecal intubation among the consecutive blocks of 20 procedures. The red line represents the cap group and the blue line represents the non-cap group. TCS, total colonoscopy.

exceeded 60 cases. Although there may be other causes, it was considered that this was probably as the novice endoscopists were not accustomed to endoscopic manipulation itself in the first 60 cases. Additionally, at Showa University Northern 
Yokohama Hospital., it is a rule that the endoscope should never be pushed until entering the descending colon. As the endoscopic insertion technique itself is an advanced technique, doctors are obligated to receive technical lectures and practice on colon models prior to performing the procedures on patients.

In the present study, other factors were considered to increase the difficulty of some procedures. Several studies have described the progress of trainees and have indicated that factors, such as abdominal surgery history, BMI, sex and age of patients can increase the difficulty of insertion (24-27). In fact, it is not easy to examine and select patients for this procedure. In the present study, patients with characteristics that could lead to a technically difficult colonoscopy were enrolled; thus, it was considered that this is the reason for the fact that the learning curve of the present study was lower than that in a previous study that had excluded such patients $(6,21)$.

The wavy cap is shorter than the conventional cap; however, its shape does not cause the loss of the endoscopic image. Therefore, the wavy cap does not present an obstacle during observation, which enables observation with a magnifying endoscopy as clearly as when without the cap. In the present study, the cap proved to be useful when trainees were in the process of mastering the technique of magnified endoscopy. The present study did not compare the performance of TCS with a wavy cap vs. conventional caps. However, a previous study reported no differences in insertion rate and time between CAC and cuff-assisted colonoscopy (28).

The present study has several limitations. First, it was a single-center study. Second, only 5 of the trainees underwent colonoscopy training, and there were only approximately 100 cases assigned to each trainee. Third, this was not a randomized case study. Fourth, the present study could not compare the performance of the wavy cap in polyp detection and cecal intubation compared with the conventional cap, as Showa University Northern Yokohama Hospital. does not use the conventional cap. Finally, $18.1 \%$ of the patients had a history of colorectal surgery. The degree of difficulty of the colonoscopy may vary depending on the location of the previous surgery. However, it was considered that the patients included in the present study were examined by trainees in a manner that resembled actual clinical practice.

In conclusion, the results of the current prospective trial suggest that a wavy cap on the tip of the colonoscope is useful for increasing the cecal intubation rate, decreases the insertion time, and allows for a steep learning curve for novice endoscopists.

\section{Acknowledgements}

The authors would like to thank Dr Chiaki Nishimura from CN Medical Research for providing advice regarding the statistical analysis, and Dr Nobunao Ikehara for providing beneficial suggestions. Part of the present study was presented at the Digestive Disease Week 2016, San Diego, CA, USA, May 1, 2016 (poster presentation).

\section{Funding}

No funding was received.

\section{Availability of data and materials}

All data generated or analyzed during this study are included in this published article or are available from the corresponding author on reasonable request.

\section{Authors' contributions}

NT was involved in the study conception and design, acquisition of data, analysis and interpretation of data, statistical analysis, and in the drafting of the manuscript. SEK was involved in study supervision, the conception and design of the study, provided critical revision and gave the final approval of the manuscript. YM was involved in the study conception and design, acquisition of data, and in the analysis and interpretation of data. MK was involved in the study conception and design and acquisition of data. TS and YK collected data, and provided and cared for patients in the study. MM was involved in the analysis and interpretation of the data, and in the critical revision of the article for important intellectual content. TK, $\mathrm{TH}$ and $\mathrm{KW}$ collected data, and provided and cared for patients in the study. HM was involved in study supervision, auditing, collection of data, and provided and cared for the patients in the study. TB and FI were involved in study supervision, data collection and auditing. All authors have read and approved the final manuscript.

\section{Ethics approval and consent to participate}

The study protocol was approved by the Ethics Committee at Showa University Northern Yokohama Hospital (no. 1105-03). The study was registered at ClinicalTrials.gov under the identifier NCT01400087, and it was conducted in accordance with the Declaration of Helsinki. All patients provided written informed consent prior to participation in the study.

\section{Patient consent for publication}

Not applicable.

\section{Competing interests}

The authors declare that they have no competing interests.

\section{References}

1. Winawer SJ, Zauber AG, Ho MN, O'Brien MJ, Gottlieb LS, Sternberg SS, Waye JD, Schapiro M, Bond JH, Panish JF, et al; The National Polyp Study Workgroup: Prevention of colorectal cancer by colonoscopic polypectomy. N Engl J Med 329: 1977-1981, 1993.

2. Citarda F, Tomaselli G, Capocaccia R, Barcherini S and Crespi M; Italian Multicentre Study Group: Efficacy in standard clinical practice of colonoscopic polypectomy in reducing colorectal cancer incidence. Gut 48: 812-815, 2001.

3. Zauber AG, Winawer SJ, O'Brien MJ, Lansdorp-Vogelaar I, van Ballegooijen M, Hankey BF, Shi W, Bond JH, Schapiro M, Panish JF, et al: Colonoscopic polypectomy and long-term prevention of colorectal-cancer deaths. N Engl J Med 366: 687-696, 2012.

4. Dafnis G, Granath F, Påhlman L, Hannuksela H, Ekbom A and Blomqvist P: The impact of endoscopists' experience and learning curves and interendoscopist variation on colonoscopy completion rates. Endoscopy 33: 511-517, 2001. 
5. Lee SH, Chung IK, Kim SJ, Kim JO, Ko BM, Hwangbo Y, Kim WH, Park DH, Lee SK, Park CH, et al: An adequate level of training for technical competence in screening and diagnostic colonoscopy: A prospective multicenter evaluation of the learning curve. Gastrointest Endosc 67: 683-689, 2008.

6. Chung JI, Kim N, Um MS, Kang KP, Lee D, Na JC, Lee ES, Chung YM, Won JY, Lee KH, et al: Learning curves for colonoscopy: A prospective evaluation of gastroenterology fellows at a single center. Gut Liver 4: 31-35, 2010

7. Spier BJ, Benson M, Pfau PR, Nelligan G, Lucey MR and Gaumnitz EA: Colonoscopy training in gastroenterology fellowships: Determining competence. Gastrointest Endosc 71 319-324, 2010.

8. Matsushita M, Hajiro K, Okazaki K, Takakuwa H and Tominaga M: Efficacy of total colonoscopy with a transparent cap in comparison with colonoscopy without the cap. Endoscopy 30: 444-447, 1998

9. Kondo S, Yamaji Y, Watabe H, Yamada A, Sugimoto T, Ohta M, Ogura K, Okamoto M, Yoshida H, Kawabe T, et al: A randomized controlled trial evaluating the usefulness of a transparent hood attached to the tip of the colonoscope. Am J Gastroenterol 102: 75-81, 2007.

10. Horiuchi A and Nakayama Y: Improved colorectal adenoma detection with a transparent retractable extension device. Am J Gastroenterol 103: 341-345, 2008.

11. Shida T, Katsuura Y, Teramoto O, Kaiho M, Takano S, Yoshidome $\mathrm{H}$ and Miyazaki M: Transparent hood attached to the colonoscope: Does it really work for all types of colonoscopes? Surg Endosc 22: 2654-2658, 2008.

12. Harada Y, Hirasawa D, Fujita N, Noda Y, Kobayashi G, Ishida K, Yonechi M, Ito K, Suzuki T, Sugawara T, et al: Impact of a transparent hood on the performance of total colonoscopy: A randomized controlled trial. Gastrointest Endosc 69: 637-644, 2009.

13. Lee YT, Lai LH, Hui AJ, Wong VW, Ching JY, Wong GL, Wu JC, Chan HL, Leung WK, Lau JY, et al: Efficacy of cap-assisted colonoscopy in comparison with regular colonoscopy: A randomized controlled trial. Am J Gastroenterol 104: 41-46, 2009.

14. Rastogi A, Bansal A, Rao DS, Gupta N, Wani SB, Shipe T, Gaddam S, Singh V and Sharma P: Higher adenoma detection rates with cap-assisted colonoscopy: A randomised controlled trial. Gut 61: 402-408, 2012.

15. Desai M, Sanchez-Yague A, Choudhary A, Pervez A, Gupta N, Vennalaganti P, Vennelaganti S, Fugazza A, Repici A, Hassan C and Sharma P: Impact of cap-assisted colonoscopy on detection of proximal colon adenomas: systematic review and meta-analysis. Gastrointest Endosc 86: 274-281, 2017.

16. Kim SY, Park HJ, Kim H-S, Park DI, Cha JM, Park SJ, Choi H, Shin JE, Eun CS, Kim JO, et al: Cap-assisted chromoendoscopy using a mounted cap versus standard colonoscopy for adenoma detection. Am J Gastroenterol 115: 465-472, 2020.
17. de Wijkerslooth TR, Stoop EM,Bossuyt PM, Mathus-Vliegen EM, Dees J, Tytgat KM, van Leerdam ME, Fockens P, Kuipers EJ and Dekker E: Adenoma detection with cap-assisted colonoscopy versus regular colonoscopy: A randomised controlled trial. Gut 61: 1426-1434, 2012.

18. Hewett DG and Rex DK: Cap-fitted colonoscopy: A randomized, tandem colonoscopy study of adenoma miss rates. Gastrointest Endosc 72: 775-781, 2010

19. Ng SC, Tsoi KK, Hirai HW, Lee YT, Wu JC, Sung JJ, Chan FK and Lau JY: The efficacy of cap-assisted colonoscopy in polyp detection and cecal intubation: A meta-analysis of randomized controlled trials. Am J Gastroenterol 107: 1165-1173, 2012.

20. Kim HH, Park SJ, Park MI, Moon W and Kim SE: Transparent-cap-fitted colonoscopy shows higherperformance with cecal intubation time in difficult cases. World J Gastroenterol 18: 1953-1958, 2012

21. Kim DJ, Kim HW, Park SB, Kang DH, Choi CW, Hong JB, Ji BH and Lee CS: Efficacy of cap-assisted colonoscopy according to lesion location and endoscopist training level. World $\mathrm{J}$ Gastroenterol 21: 6261-6270, 2015.

22. Zhang T, Xu LJ, Xiang J, He Z, Peng ZY, Huang GM, Ji GZ and Zhang FM: Cap-assisted endoscopic sclerotherapy for hemorrhoids: Methods, feasibility and efficacy. World J Gastrointest Endosc 7: 1334-1340, 2015

23. Silva LC, Arruda RM, Botelho PFR, Taveira LN, Giardina KM, de Oliveira MA, Dias J, Oliveira CZ, Fava G and Guimarães DP: Cap-assisted endoscopy increases ampulla of Vater visualization in high-risk patients. BMC Gastroenterol 20: 214, 2020.

24. Oh SY, Sohn CI, Sung IK, Park DI, Kang MS, Yoo TW, Park JH, Kim HJ, Cho YK, Jeon WK, et al: Factors affecting the technical difficulty of colonoscopy. Hepatogastroenterology 54: 1403-1406, 2007.

25. Shah HA, Paszat LF, Saskin R, Stukel TA and Rabeneck L: Factors associated with incomplete colonoscopy: A population-based study. Gastroenterology 132: 2297-2303, 2007.

26. Bernstein C, Thorn M, Monsees K, Spell R and O'Connor JB: A prospective study of factors that determine cecal intubation time at colonoscopy. Gastrointest Endosc 61: 72-75, 2005

27. Anderson JC, Messina CR, Cohn W, Gottfried E, Ingber S, Bernstein G, Coman E and Polito J: Factors predictive of difficult colonoscopy. Gastrointest Endosc 54: 558-562, 2001.

28. Sola-Vera J, Catalá L, Uceda F, Picó MD, Pérez Rabasco E, Sáez J, Jiménez N, Arjona MD, Fernández M, Girona E, et al: Cuff-assisted versus cap-assisted colonoscopy for adenoma detection: Results of a randomized study. Endoscopy 51: 742-749, 2019.

This work is licensed under a Creative Commons Attribution-NonCommercial-NoDerivatives 4.0 International (CC BY-NC-ND 4.0) License. 